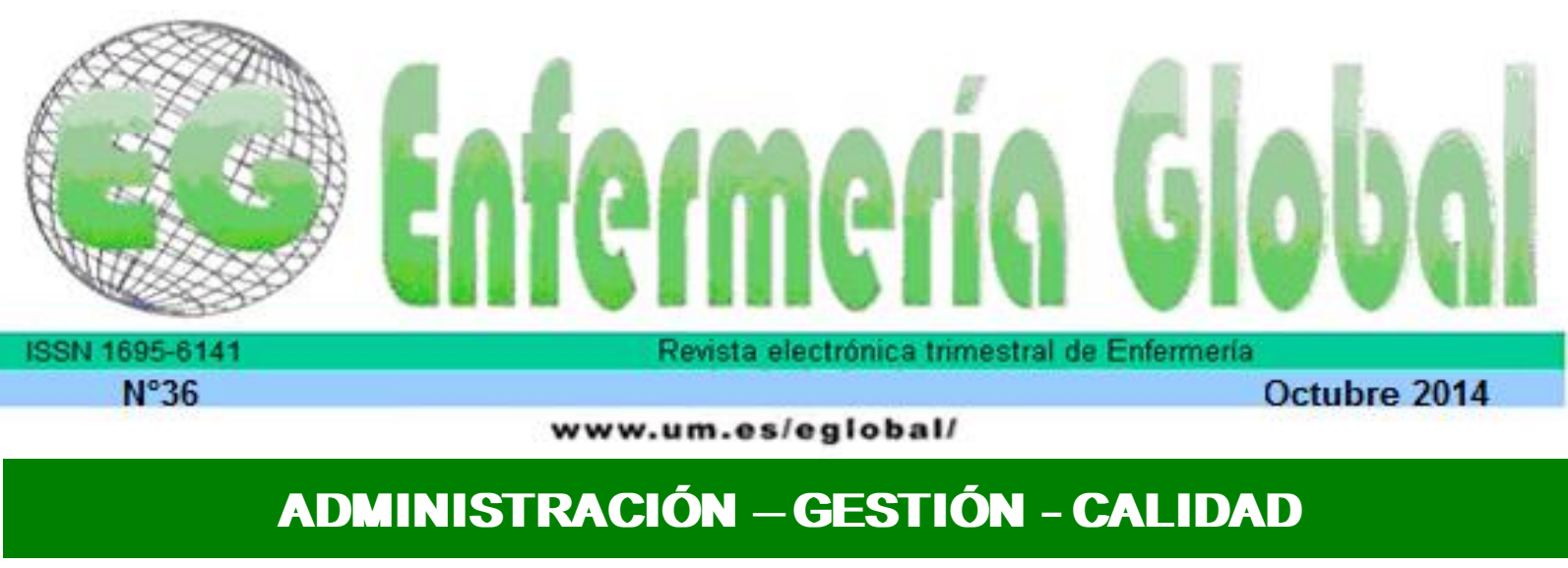

\title{
Conocimiento del equipo de enfermería sobre la muerte encefálica y la donación de órganos
}

Compreensão da equipe de enfermagem sobre a morte encefálica e a doação de órgãos

Comprehension the nursing team on brain death and organ donation

${ }^{*}$ Freire, Izaura Luzia Silvério ** Oliveira de Mendonça, Ana Elza *** Bessa de Freitas, Marcelo ${ }^{* * * *}$ Melo, Gabriela de Sousa Martins ${ }^{* * * *}$ Costa, Isabelle Katherinne Fernandes ${ }^{* * * * *}$ Torres, Gilson de Vasconcelos.

\begin{abstract}
*Profesora de la Escuela de Enfermería de la Universidad Federal de Rio Grande do Norte/UFRN. Email: izaurafreire@hotmail.com **Enfermera intensivista de la UCl general del Hospital Universitario Onofre Lopes /UFRN. Doctoranda en Ciencias de la Salud /UFRN. ***Enfermero de la Secretaría de Estado de Salud Pública de Rio Grande do Norte. Especialista en Terapia Intensiva y Educación. ${ }^{* * * *}$ Enfermera. Doctoranda del Programa de Postgraduación en Enfermería de la Universidad Federal de Rio Grande do Norte ${ }^{* * * * *}$ Doctora en Enfermería. Profesora Adjunta 1 de la Universidad Federal de Rio Grande do Norte. ${ }^{* * * * * * P o s t d o c t o r ~ e n ~ E n f e r m e r i ́ a . ~ P r o f e s o r ~ T i t u l a r ~ d e ~ l a ~}$ Universidad Federal de Rio Grande do Norte.Brasil.
\end{abstract}

\section{Palabras clave: Enfermería; Obtención de tejidos y órganos; muerte encefálica Palavras-chave: Enfermagem; Obtenção de tecidos e órgãos; Morte encefálica Keywords: Nursing; Tissue and organ procurement; Brain death}

\section{RESUMEN}

Objetivo: Identificar el conocimiento del equipo de enfermería sobre la muerte encefálica (ME) y la donación de órganos y tejidos.

Método: Estudio descriptivo, cuantitativo, realizado en seis hospitales de Natal / RN con 68 enfermeras. Los datos fueron recolectados a través de un cuestionario estructurado, realizado análisis descriptivo y análisis temático de contenidos. El estudio fue aprobado por el Comité de Ética en Investigación.

Resultados: De los 68 profesionales, el 51,5\% eran técnicos de enfermería, 77,9\% dijeron que se sienten preparados para ayudar a los pacientes ME. Los criterios para el diagnóstico de ME, el 94,1\% citaron la falta de actividad cerebral detectada por los exámenes complementarios. El mantenimiento 
de la temperatura corporal $(82,4 \%)$ fue la advertencia principal mencionada en el mantenimiento del donante potencial. Del proceso de donación, la entrevista con la familia fue la más citada $(82,4 \%)$.

Conclusión: Existe una falta de conocimiento teórico y práctico del equipo de enfermería, lo que demuestra la necesidad de invertir en las estrategias educativas.

\section{RESUMO}

Objetivo: Identificar a compreensão da equipe de enfermagem acerca da morte encefálica (ME) e da doação de órgãos e tecidos.

Método: Estudo descritivo, quantitativo realizado em seis hospitais de Natal/RN com 68 profissionais de enfermagem. Os dados foram coletados através de questionário estruturado, realizada analise descritiva e análise temática de conteúdos. O estudo obteve parecer favorável do Comitê de Ética em Pesquisa.

Resultados: Dos 68 profissionais, $51,5 \%$ era técnico de enfermagem; 77,9\% afirmaram sentir-se preparados para assistir paciente em ME. Dos critérios para o diagnóstico da ME, 94,1\% citou ausência de atividades encefálicas detectas por exames complementares. A manutenção da temperatura corporal $(82,4 \%)$ foi o principal cuidado mencionado na manutenção do potencial doador. Do processo de doação, a entrevista com a família foi a mais citada $(82,4 \%)$.

Conclusão: Evidenciou-se falta de conhecimento teórico-prático da equipe de enfermagem, demonstrando a necessidade de se investir em estratégias educacionais.

\section{ABSTRACT}

Objective: Identify the understanding of the nursing team about brain death (BD) and the donation of organs and tissues.

Method: Descriptive, quantitative study conducted in six hospitals in Natal/RN with 68 nursing staff. Data were collected through a structured questionnaire, realized descriptive analysis and thematic analysis of content. The study was approved by the Research Ethics Committee.

Results: Of the 68 professionals, $51,5 \%$ were nursing technician; $77,9 \%$ affirmed feeling prepared to assist patient in BD. Among the criteria for the diagnosis of BD, $94,1 \%$ cited absence of brain activity detects by complementary exams. The maintenance of body temperature $(82,4 \%)$ was the main care mentioned in maintenance of the potential donor. Of the donation process, the interview with the family was the most cited $(82,4 \%)$

Conclusion: It was evidenced lack of theoretical and practical knowledge of the nursing team, demonstrating the need to invest in educational strategies.

\section{INTRODUCCIÓN}

Los aspectos culturales del proceso de muerte y morir se modificaron a lo largo de los años, una vez que dejó de ocurrir en las casas de las personas y fue transferido a los hospitales, donde se institucionalizó, medicalizaó y fue repetidamente pospuesto por el uso de la sofisticación tecnológica. Por tanto, ante este nuevo escenario de muerte están las tecnologías médicas que llevaron al trasplante de órganos ${ }^{(1)}$.

Refuerza que la historia del trasplante siempre estuvo vinculada a la definición de muerte encefálica (ME), situación en que el individuo se torna apto a la donación de órganos y tejidos. Sin embargo, se percibe que este concepto todavía es intrincado por cuestiones filosóficas, religiosas, sociales y emocionales. Esto porque la muerte aún es considerada un tabú en la sociedad occidental y perturba sobremanera a los 
profesionales de salud en su ambiente de trabajo, teniendo en cuenta que su formación se orienta a la preservación de la vida, para la curación de las enfermedades, perder un paciente por muerte muchas veces significa un fracaso profesional $^{(1)}$.

Por ello, el conocimiento y la aceptación del diagnóstico de ME es necesario, tanto para los profesionales de salud como para la población, dado que la donación de los órganos y tejidos de las personas que se encuentran en ese estado puede representar la única o incluso la última suerte de alternativa terapéutica para pacientes con varios tipos de enfermedades terminales.

Cabe enfatizar que la Política Nacional de Trasplantes está fundamentada en la Constitución Federal Brasileña de 1988 y por la Ley no. 9434/97 y Ley no 10.211/01 que dispone sobre la retirada de órganos, tejidos y partes del cuerpo humano para fines de trasplante ${ }^{(2-3)}$.

Con la creciente demanda de trasplantes en el país, en 1997, se creó el Sistema Nacional de Transplante (SNT), vinculado al Ministerio de Salud. En la esfera federal, existe la Central Nacional de Notificación, Captación y Distribución de Órganos (CNNCDO) y en las demás unidades de la federación las Centrales de Notificación, Captación y Distribuición de Órganos (CNCDOs). Son parte también de ese sistema, las listas únicas de receptores, el registro y autorización de hospitales trasplantadores y de los equipos especializados, además del establecimiento de los criterios de financiación para el sector ${ }^{(2)}$.

En lo tocante al diagnóstico de la $\mathrm{ME}$, este está respaldado, en Brasil, por la Resolución del Consejo Federal de Medicina (CFM) $n^{\circ} 1.480 / 97$ que define la ME como la parada completa e irreversible de todas las funciones encefálicas, tanto de los hemisferios como del tronco cerebral, lo que significa interrupción definitiva de todas las actividades del encéfalo ${ }^{(3)}$.

De acuerdo con esta resolución, para la confirmación del diagnóstico de $\mathrm{ME}$ es indispensable la realización de dos exámenes neurológicos, que deben ser efectuados por dos médicos diferentes, uno de ellos obligatoriamente neurólogo 0 neurocirujano, no integrantes del equipo de remoción y trasplante. Estos exámenes buscan evaluar la integridad del tronco encefálico. El intervalo mínimo entre un examen y otro es de seis horas en pacientes de más de dos años. Es obligatoria también la realización de examen complementario, para mostrar ausencia de actividad eléctrica y metabólica encefálica o de perfusión sanguínea encefálica ${ }^{(4)}$.

En cuanto a los cuidados relacionados con el potencial donante (PD), estos deben ser desarrollados en Unidad de Cuidados Intensivos (UCI), contar con infraestructura apropiada, recursos humanos especializados, materiales específicos y tecnologias necesarias para el diagnóstico, monitorización y terapia, de acuerdo con la Resolución de la Directoría Colegiada (RDC) no 7 de 24 de febrero de 2010, que dispone sobre los requisitos mínimos para el funcionamiento de la UCI y la RDC n 50 , de 21 de febrero de 2002, que dispone sobre los proyectos físicos de establecimientos asistenciales de salud, incluyendo las $\mathrm{UCls}^{(5)}$.

Se enfatiza que estos cuidados son desgastantes, teniendo en cuenta que se configura como paciente grave que requiere atención permanente debido a las 
alteraciones fisiológicas derivadas de la $M E$, que si no son controladas de forma efectiva, pueden inviabilizar la donación de uno o más órganos para trasplante ${ }^{(6)}$.

De este modo, la enfermería tiene un papel fundamental en la asistencia al PD de órganos y tejidos, que necesita de cuidados específicos e intensivos. La asistencia que el equipo de enfermería presta engloba no sólo al paciente, sino también a la familia y la posible donación, así como la preocupación con los órganos y el posible receptor. Se destaca la relevancia de este estudio, toda vez que pretende contribuir a la elaboración de estrategias de educación continua que complementen la actuación efectiva de la enfermería frente al PD de órganos y tejidos, asegurando la viabilización de esos injertos para el transplante.

Basado en el presupuesto de que la enfermería junto a otros profesionales es fundamental en el cuidado al paciente en ME y en la donación de órganos y tejidos, el estudio tiene como objetivo Identificar la comprensión del equipo de enfermería acerca de la ME y de la donación de órganos y tejidos.

\section{MATERIAL Y MÉTODO}

Se trata de un estudio seccional, descriptivo, con abordaje cuantitativo, realizado en seis unidades hospitalarias de Natal/RN, de las que tres eran de la red pública y tres de la privada, todos acreditados por el SNT para retirada y trasplante de órganos y tejidos.

La muestra estuvo compuesta por 68 profesionales de enfermería, seleccionados a partir de una muestra por accesibilidad, que atendieron a los siguientes criterios de inclusión: estar en ejercicio activo en esos hospitales en el periodo del estudio y trabajar en unidades que reciben PDs (UCI o sector de emergencia) y como criterios de exclusión responder a menos del $80 \%$ de la parte III del cuestionario.

La investigación fue aprobada por el Comité de Ética e Investigación del Hospital Universitario Onofre Lopes bajo el no 414/10 e CAAE 007.0.294.000-10, respetando la normatización de la Resolución 196/96 del Consejo Nacional de Salud, en lo que se refiere a los aspectos éticos observados cuando en la realización de la investigación se incluyen seres humanos. También se solicitó a los profesionales participantes la firma del Término de Consentimiento Libre y Esclarecido (TCLE), tras explicación sobre el objetivo del estudio.

El proceso de colecta de datos ocurrió entre los meses de enero a marzo de 2013. Los datos fueron colectados a través de la aplicación de cuestionario considerado como auto-relato estructurado, compuesto por las siguientes partes: parte I contiene datos de identificación personal, como: edad, sexo, escolaridad, estado civil y religión. En la parte II están los datos de identificación profesional: formación profesional, tiempo de servicio en enfermería, hospital en que trabaja (público o privado), institución de formación profesional básica (pública 0 privada), curso de perfecionamiento y/o especialización. Parte III con los datos relacionados a la asistencia de enfermería: ¿trabaja o ya trabajó con este tipo de paciente?; ¿se siente preparado para asistir a estos pacientes?; ¿donde adquirió estas informaciones?; ¿existe algún obtáculo considerado importante que dificulte asistir a estos pacientes?; ¿cuáles son? 
La parte IV del instrumento está formada por preguntas abiertas relacionadas con el conocimiento del equipo de enfermería sobre la ME y cuidados con el PD de órganos y tejidos: criterios evaluados en el diagnóstico de $\mathrm{ME}$; cuidados generales y específicos prestados al paciente en ME, PD de órganos y tejidos; etapas del proceso de donación de órganos.

Los datos oriundos de las cuestiones cerradas del instrumento se organizaron en una planilla electrónica y se presentaron en tablas, con frecuencia relativa y absoluta. Las preguntas abiertas fueron sometidas a análisis temático de contenidos, que prevé la organización de las informaciones por medio del pre-análisis, exploración del material, tratamiento de los resultados e interpretación. Las categorías empíricas emergidas fueron procesadas electrónicamente y presentadas en forma de cuadros. Para análisis de los datos se utilizó Microsoft Excel 2007 y un software estadístico.

\section{RESULTADOS}

Con relación a la población estudiada, de los 68 profesionales participantes, la mayoría era de sexo femenino $(89,7 \%)$, con faja etaria de 30 a 39 años, casado $(44,1 \%)$ y católico $(70,6 \%)$. La tabla I describe la caracterización de los profesionales de enfermería.

Tabla I. Caracterización de los investigados en cuanto al sexo, edad, estado civil y religión. Natal/RN, 2013

\begin{tabular}{llcc}
\hline & CARACTERIZACIÓN & n & \% \\
\hline \multirow{2}{*}{ Sexo } & Femenino & 61 & 89,7 \\
& Masculino & 7 & 10,3 \\
\multirow{3}{*}{ Edad } & $18-29$ años & 13 & 19,1 \\
& 30-39 años & 24 & 35,3 \\
& 40-49 años & 21 & 30,9 \\
& 50 o más & 10 & 14,7 \\
\multirow{4}{*}{ Estado Civil } & Casado & 30 & 44,1 \\
& Soltero & 26 & 38,2 \\
& Divorciado & 4 & 5,9 \\
\multirow{3}{*}{ Religión } & Unión estable & 7 & 10,3 \\
& Católico & 48 & 70,6 \\
& Evangélico & 15 & 22,1 \\
& Espirita & 5 & 7,4 \\
\hline
\end{tabular}

Al considerar la formación básica y profesional, conforme lo presentado en la tabla II, $67,6 \%$ se formó en instituciones públicas de enseñanza básica y 51,5\% eran técnicos de enfermería. Con relación a la escolaridad, 42,6\% tenían enseñanza media completa. El tiempo de servicio en enfermería se concentró en la faja de más de 20 años $(29,4 \%)$ y $52,9 \%$ trabajaban en instituciones hospitalarias de carácter público. La mayoría afirmó haber realizado curso de perfeccionamiento / especialización (80,9\%). 
Tabla II. Caracterización profesional de los participantes de la investigación. Natal/RN, 2013

\begin{tabular}{llcc}
\hline \multirow{2}{*}{ CARACTERIZACIÓN PROFESIONAL } & \multicolumn{2}{c}{ TOTAL } \\
\cline { 2 - 4 } Institución de formación & Pública & 46 & $\mathbf{\%}$ \\
básica & Privada & 22 & 67,6 \\
& Enfermero & 32 & 32,4 \\
Formación profesional & Téc. de enfermería & 35 & 47,1 \\
& Aux. de enfermería & 1 & 51,5 \\
& Enseñanza media & 29 & 1,5 \\
Escolaridad & Enseñanza superior & 17 & 42,6 \\
& Postgraduación & 22 & 25,0 \\
& Menos de 1 año & 1 & 32,4 \\
Tiempo de servicio en & 1 a 4 años & 8 & 1,5 \\
enfermería & 5 a 9 años & 14 & 11,8 \\
& 10 a 14 años & 14 & 20,6 \\
& 15 a 20 años & 11 & 20,6 \\
Institución de trabajo & $>$ de 20 años & 20 & 16,2 \\
Curso de perfeccionamiento/ & Sim & 32 & 29,4 \\
especialización & Privada & 47,1 \\
\hline
\end{tabular}

En cuanto a la experiencia de trabajo con pacientes en ME, 91,3\% declararon que trabajan o ya trabajaron con estos pacientes y $77,9 \%$ afirmaron que se sienten preparados para asistirlos, de estos $45,3 \%$ informaron haber adquirido conocimiento sobre la asistencia a esa población en cursos, $34,0 \%$ en coferencias, $9,4 \%$ en la graduación y $47,2 \%$ otras formas, se destaca que algunos participantes listaran más de una opción.

Al preguntar si existe obstáculo considerado importante que dificulte la asistencia al paciente en ME, $58,8 \%$ afirmaron que no, con todo de los que dijeron existir $(41,2 \%)$ las principais dificultades apuntadas fueron: falta de conocimiento y poca preparación del equipo (67,9\%); falta de insumos, estructura y recursos humanos adecuados $(39,3 \%)$; falta de importancia dada a ese paciente $(17,9) ; 7,1 \%$ relación con los familiares; y $7,1 \%$ no al seguimiento del protocolo de ME. Vale la pena señalar que hubo más de una respuesta por profesional que declaró existir dificultades.

Considerando que las cuestiones relacionadas con el conocimiento del equipo de enfermería sobre la ME y proceso de donación de órganos y tejidos eran abiertas, se describieron diversas respuestas, algunas no se encuadraron en el contexto preguntado, las demás se categorizaron a partir del análisis del contenido.

De acuerdo con las respuestas expuestas en la figura 1 sobre los criterios evaluados en el diagnóstico de ME, se percibe un predominio de la ausencia de actividad encefálica detectada por exámenes complementarios $(94,1 \%)$, seguido por realización de exámenes neurológicos $(72,1 \%)$ y coma arreactivo y arreflexivo $(51,5 \%)$. 
Erróneamente, entrevistados refirieron que la realización de tomografia computadorizada de cráneo $(11,8 \%)$ y reflejos córtico-medulares $(1,5 \%)$ eran criterios utilizados para el diagnóstico y 2,9\% no recordaban cuáles eran los criterios.

Figura 1. Distribución de las respuestas de los participantes acerca de los criterios evauados en el diagnóstico de muerte encefálica. Natal/RN, 2013

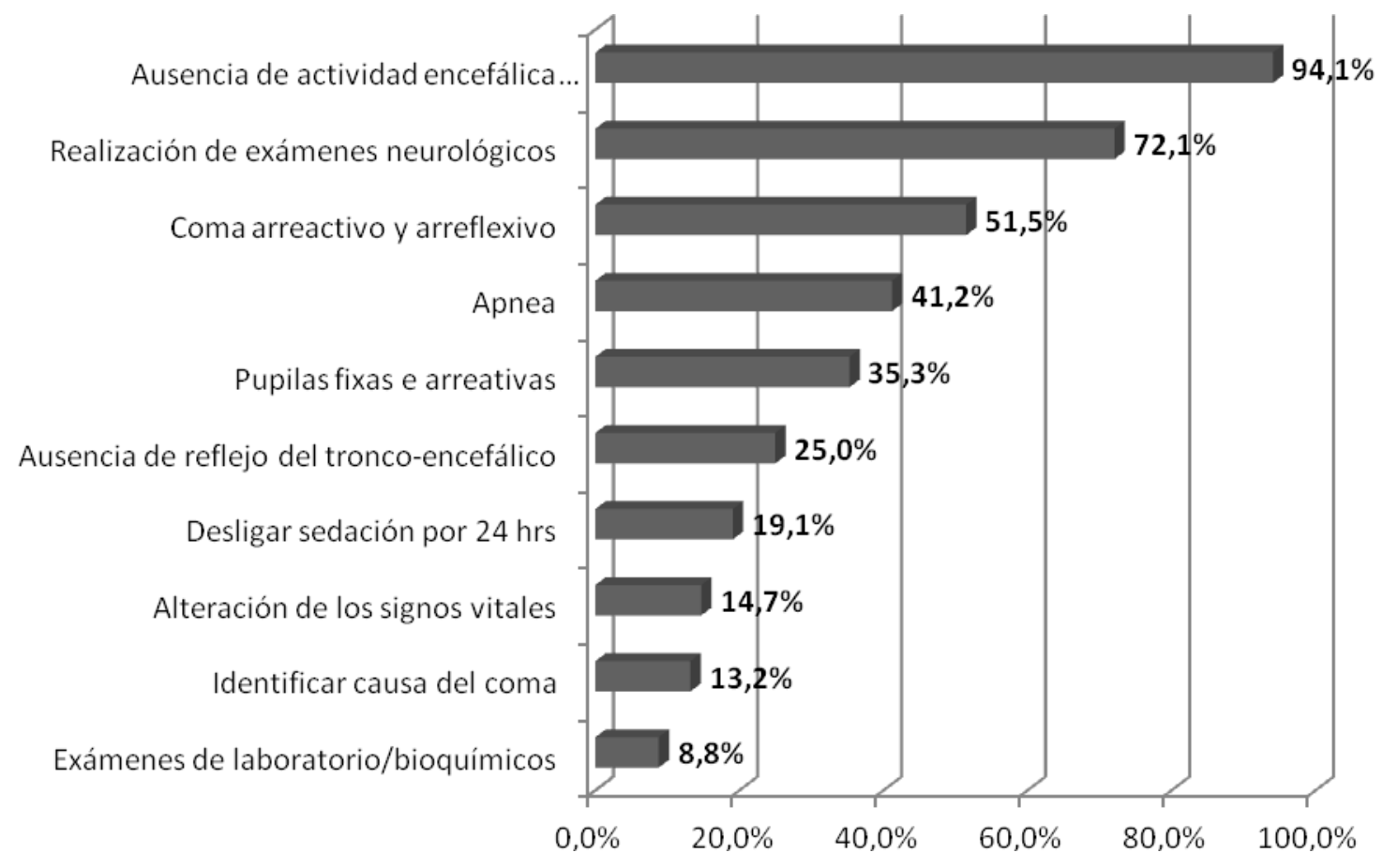

La figura 2 representa las respuestas de los participantes con relación a los cuidados generales y específicos prestados al paciente en muerte encefálica. Se percibe que la mayoría citó cuidados referentes al mantenimiento de la temperatura corporal $(82,4 \%)$, monitorización hemodinámica $(70,6 \%)$, control hidroelectrolítico con sondaje vesical $(64,7 \%)$ e higiene corporal con cambio de decúbito $(60,3 \%)$. 
Figura 2. Descripción de los principales cuidados generales y específicos prestados al paciente en muerte encefálica por los profesionals de enfermería. Natal/RN, 2013

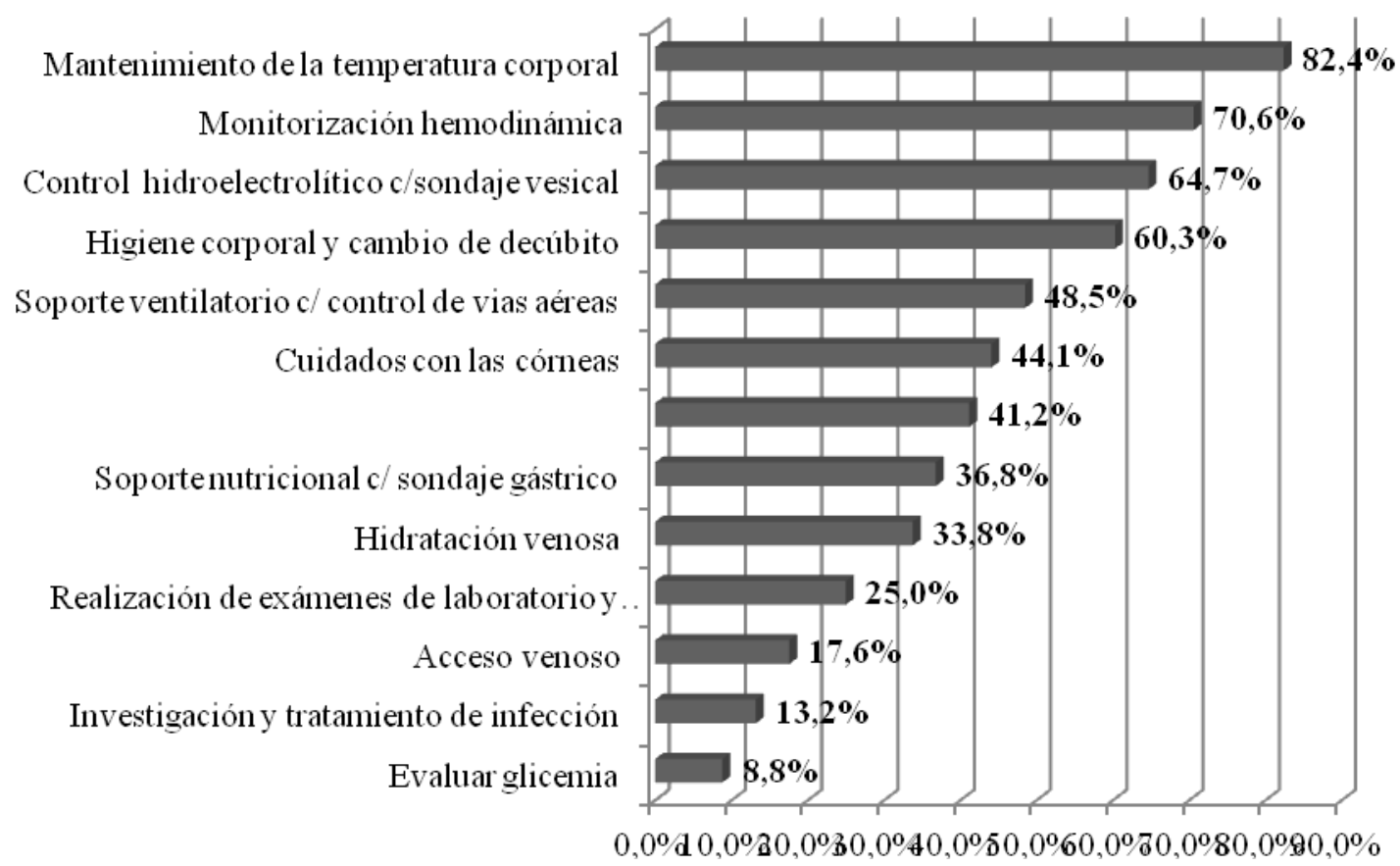

Sin embargo, entre tantas respuestas, algunas merecen ser destacadas por haber sido citadas de forma equivocada, como tres participantes que respondieron no mantener la dieta, uno refirió la retirada total de las medicaciones y uno dejó de responder a esta pregunta.

Para la evaluación de las respuestas sobre las etapas del proceso de donación de órganos y tejidos, se consideraron ocho pasos fundamentales dispuestos en la figura 3 , de los que seis obtuvieron $50 \%$ o más de respuestas, siendo la entrevista con la familia la más citada (82,4\%), seguida por el diagnóstico de ME $(67,6 \%)$ y captación de los órganos y tejidos $(66,2 \%)$, la entrega del cuerpo recompuesto a la familia fue la que obtuvo menor peorcentaje $(17,6 \%)$.

Figura 3. Conocimiento de los profesionales de enfermería sobre las etapas del proceso de donación de órganos y tejidos. Natal/RN, 2013

\begin{tabular}{|lcc|}
\hline \multicolumn{1}{|c}{ CONOCIMIENTO SOBRE LAS ETAPAS DEL } & \multicolumn{2}{c|}{ TOTAL } \\
\cline { 2 - 3 } \multicolumn{1}{c}{ PROCESO DE DONACIÓN DE ÓRGANOS Y } & $\mathbf{n}=\mathbf{6 8}$ & $\mathbf{\%}$ \\
\hline Identificación del potencial donante & 34 & 50,0 \\
Notificar la CNCDO u OPO & 28 & 41,2 \\
Evaluación del potencial donante & 34 & 50,0 \\
Mantenimiento del potencial donante & 36 & 52,9 \\
Diagnóstico de muerte encefálica & 46 & 67,6 \\
Entrevista con la familia & 56 & 82,4 \\
Captación de órganos y tejidos & 45 & 66,2 \\
Entrega el cuerpo recompuesto a la familia & 12 & 17,6 \\
\hline
\end{tabular}


De entre las respuestas de los sujetos del estudio, 4,4\% de los profesionales no respondieron o lo hicieron de forma incoherente.

\section{DISCUSIONES}

Los resultados encontrados en la presente investigación sobre las características personales de los profesionales de enfermería convergen con estudios nacionales e internacionales, donde se revela el predominio de un individuo de sexo femenino, adulto joven, casado y católico ${ }^{(7)}$.

En relación a la formación de los profesionales de enfermería, se percibe mayor porcentaje del nivel medio, este hecho se justifica por el porcentaje de técnicos en enfermería, ya que este es uno de los requisitos para la obtención de ese título. Sin embargo, en los últimos tiempos ha habido una gran demanda de cursos de nivel superior por parte de los profesionales de nivel técnico, así como mayor número de enfermeros en cursos de posgraduación.

Sobre el predominio de profesionales de enfermería con elevado tiempo de servicio, se entiende que este profesional esté más experimentado y preparado, al estar más cerca de la jubilación. También los profesionales con poco tiempo de servicio procuran suplir las lagunas existentes por la falta de experiencia y/o preparación a través de la busca constante de conocimientos, así se actualizan a través de congresos, especializaciones y participación en cursos de perfeccionamiento y capacitación proporcionados por la institución empleadora.

La mayoría de los participantes refirió sentirse preparada para asistir a los pacientes en ME, con todo, al relacionar el porcentaje de etapas citadas dentro del diagnóstico de ME y proceso de donación de órganos y tejidos se percibe que pocas etapas obtuvieron valores superiores al $70,0 \%$ y que ningún profesional enumeró todas las etapas fundamentales tanto en el diagnóstico de ME, mantenimiento y proceso de donación, observándose que el conocimiento no corresponde con la realidad citada.

Se sabe que los pacientes en ME requieren cuidados específicos por tratarse de pacientes gravemente inestables, que precisan, además de un ambiente especializado para el tratamiento intensivo de sus funciones vitales y del mantenimiento de los órganos, de recursos humanos que mantengan conocimientos sobre la fisiopatología de la ME, así como de los cuidados específicos del mantenimiento, objetivando la disponibilidad de órganos para trasplantes ${ }^{(8)}$.

El proceso de educación se torna fundamental en esta área, especialmente porque la participación de la sociedad y, sobre todo, de los profesionales de salud es uno de los factores decisivos para el éxito de los programas de trasplante. Un grupo que merece ser destacado son los estudiantes, especialmente del área de salud ${ }^{(9)}$.

Estudio desarrollado con estudiantes de enfermería y medicina en Brasil evidenció poco conocimiento de estos sobre la ME y sus aspectos, así como con los cuidados con el PD, hecho este asociado a las deficiencias de los currículos de graduación, lo que es preocupante, ya que ellos serán futuros profesionales y salen muchas veces mal preparados para actuar en el área de trasplantes ${ }^{(8-9)}$.

Con relación a la existencia de obstáculos que dificultan la asistencia a los PDs, la mayoría citó falta de conocimiento y mala preparación del equipo, demostrando 
nuevamente la importancia de la adopción de estrategias que promuevan el conocimiento y el cambio en el comportamiento del profesional.

Se entiende que la mala preparación del equipo, además de generar estrés profesional, sufrimiento familiar, compromete la eficacia del proceso, siendo fundamental la educación y perfeccionamiento, buscando evitar tales factores, además de posibilitar la ampliación de la oferta de órganos y tejidos para trasplantes, acarreando beneficios a la sociedad ${ }^{(10)}$.

Paralelamente a esa realidad, algunos autores afirman que las principales causas para la no efectivación de la donación y trasplante de órganos y tejidos se deben al desconocimiento del concepto de ME tanto por la población como por los profesionales de la salud, la falta de credibilidad de los beneficios de la donación y trasplante, el rechazo de los familiares a aceptar la donación, las dificultades logísticas, la contraindicación médica y la parada cardíaca del PD ocasionada por el fallo en el mantenimiento de sus órganos ${ }^{(11-12)}$.

El proceso de donación se inicia con la identificación y notificación de un individuo que está en coma aperceptivo y arreactivo, puntuación tres en la Escala de Coma de Glasgow. Después de una cuidadosa evaluación clínica y de laboratorio de ese paciente y no identificándose contraindicaciones que representen riesgos a los receptores se tendrá un PD ${ }^{(12-13)}$.

Según la Resolución del CFM no 1.480/97, la ME deberá ser constatada para la realización de exámenes clínicos y complementarios realizados en intervalos establecidos conforme a la edad del paciente. Los parámetros clínicos observados en esas evaluaciones son: coma aperceptivo con ausencia de actividad motora supraespinal y apnea ${ }^{(4)}$.

A pesar del predominio en el estudio de la respuesta de ausencia de actividades encefálicas detectadas por exámenes complementarios, realización de exámenes neurológicos y coma arreactivo y arreflexivo relacionadas con el criterio de $\mathrm{ME}$, se percibe una discrepancia en relación a los demás criterios de evaluación, así como muchos profesionales apuntaron que quien hace el diagnóstico es el médico, sin embargo, no los excluye de la responsabilidad como aquellos que están más próximos al paciente en reconocer los signos previsibles de la ME.

Durante todo el proceso de donación se debe realizar el mantenimiento del PD con la finalidad de mantener la estabilidad hemodinámica, viabilidad y calidad de los órganos y tejidos posibles de utilización ${ }^{(12)}$.

Al prestar una asistencia sistematizada al PD, el equipo de enfermería debe tener conocimiento de las alteraciones fisiológicas derivadas de la $\mathrm{ME}$, pues ellas constituyen un complejo proceso, repercutiendo en la cantidad y calidad de los órganos a ser trasplantados. De ese modo, el equilibrio hemodinámico del PD no está solamente en los ambientes y equipamientos de alta tecnología, sino en el reconocimiento y posterior confirmación, conocimiento de los aspectos legales, prevención, detección precoz y manejo de las principales complicaciones de la ME. Ahí se consolida la importancia de un equipo eficiente y comprometido con el cuidado ${ }^{(14-15)}$. 
En los cuidados para el mantenimiento del PD los referentes para el mantenimiento de la temperatura corporal, monitorización hemodinámica y control hidroelectrolítico fueron los más citados, respectivamente, en el presente estudio. El control de la temperatura corporal es un cuidado fundamental para mantenimiento del PD, siendo función exclusiva de la enfermería el calentamiento con mantas, manta térmica, o con focos de luz dirigidos al tórax o abdomen o utilizando soluciones calentadas a temperatura de $37^{\circ}$ a $38^{\circ} \mathrm{C}$ evitando la ocurrencia de la hipotermia, que puede generar alteraciones cardiacas, disminución del transporte de oxígeno, entre otras alteraciones $^{(14-15)}$.

En cuanto a la asistencia de enfermería, esta debe atender a las necesidades fisiológicas básicas del PD y, de entre todos los cuidados, los más relevantes son: providenciar un acceso venoso central para infusión de drogas y líquidos, además de la medida de la presión venosa central; monitorización de los signos vitales; realizar el sondaje gástrico para descompresión del estómago o alimentación; mantener las dietas por via enteral. Mantenimiento de las vías aéreas superiores, con elevación de la cabecera en $30^{\circ}$ para evitar broncoaspiración. Se debe realizar sondaje vesical de demora para el control del débito y de la densidad urinaria e higiene corporal ${ }^{(14-16)}$.

Los cuidados específicos están relacionados con las alteraciones fisiológicas desencadenadas por el proceso de ME y que contribuyen a la inestabilidad del donante, como la hipertensión o hipotensión arterial, alteraciones en los fluídos, electrólitos y en el metabolismo, desequilibrio ácido básico, hipotermia y tratamiento de infecciones ${ }^{(14-16)}$.

Estudio identificó que la asistencia prestada por el equipo de enfermería al PD, generalmente es común a la de otros pacientes graves que necesitan de terapia intensiva. En el caso de un paciente en ME, normalmente se presta mayor atención al calentamiento corporal, debido a la hipotermia, y a la protección ocular a través de la humidificación, a fin de preservar las córneas, por ser las más comunes en la donación ${ }^{(13)}$.

Caso haya concordancia familiar en la donación, el profesional responsable del proceso de donación y la CNCDO pasan a considerar los demás factores para la efectivación de la donación, implementando la logística predefinida. Se hace hincapié en que antes de ser iniciada la retirada de los órganos y tejidos, la Declaración de Óbito (DO) deberá ser proporcionada en situaciones de muerte natural. En los casos de muerte por causa externa, el cuerpo deberá enviarse al Instituto Médico Legal, donde se le realizará la autopsia y emitida la DO ${ }^{(12)}$.

Para que un trasplante de órganos se produzca eficaz y legalmente, varias instancias, leyes y resoluciones están involucradas en este proceso. Como la promulgación de la Ley $n^{\circ}$ 9.434, de 04 de febrero de 1997 del CFM, que dispone sobre la retirada de órganos, tejidos y partes del cuerpo humano para fines de trasplantes, así como el Sistema Nacional de Trasplantes que está presente en cada estado brasileño a través de las Centrales de Notificación, Captación y Distribución de Órganos ${ }^{(4,17)}$.

Col la intención de ayudar las CNCDOs, el 21 de octubre de 2009 se publicó la Ordenanza GM/MS n 2.601, creándose el Plan Nacional de Implantación de las Organizaciones de Demanda de Órganos y Tejidos con objetivo de mejorar y cualificar el proceso de donación/trasplante en Brasil - que se inicia con la identificación y notificación de los probables donantes, pasando por la realización de 
los trasplantes propiamente dichos, hasta el suministro de toda la medicación inmunosupresora por el Sistema Único de Salud ${ }^{(18)}$.

En la presente investigación la entrevista con la familia fue la etapa más citada del proceso de donación de órganos y tejidos, seguida del diagnóstico de ME y captación de los órganos y tejidos $(66,2 \%)$. Autores resaltan que la asistencia prestada al paciente y familia desde el momento del ingreso hasta la solicitud de la donación influye en el modo como la familia va a reaccionar frente a esa petición. Es fundamental el reconocimiento de las experiencias vividas por los familiares, exponiendo la importancia de la consideración del sufrimiento y acogida que debe ser realizado por el equipo, en especial, por el enfermero. Ofrecer informaciones sobre la ME y la transparencia en el proceso de donación posibilita una recuperación con menos conflicto, minimizando el estrés y favoreciendo la toma de decisión en cuanto a la donación ${ }^{(19)}$.

Tras la aceptación de la donación deben providenciarse exámenes de rutina y de serologías para verificar la función de los órganos y posibles contraindicaciones a la donación, cabe al enfermero, además de sus responsabilidades en el mantenimiento del potencial donante, el marcar el horario de la cirugía de retirada de órganos, informar a los equipos de trasplantes y de enfermería del centro quirúrgico, explicitando qué órganos serán captados, orientar al equipo de enfermería, cuidador del potencial donante sobre el preoperatorio indispensable y verificar el registro y la cumplimentación correcta de los impresos como: ficha de identificación del donante, autorización de la familia y protocolo de muerte encefálica ${ }^{(20)}$.

En el proceso de trabajo de enfermería están incluidas las tres fases del proceso: donación, captación y trasplante: el inicio (notificación y busca activa de potenciales donantes), medio (documentación) y fin (distribución de los órganos y cuidado al receptor y familia). Constituyéndose así como parte de la propia ejecución del trasplante ${ }^{(9)}$.

Desgraciadamente, además de la falta de conocimiento, la enfermería enfrenta, muchas veces, condiciones precarias y sobrecarga de trabajo que hacen que la asistencia ideal y de calidad con el paciente en ME sea difícil de alcanzar. A pesar de las dificultades es evidente que la enfermería desarrolla un papel fundamental en este escenario $^{(13)}$.

Todo este proceso que envuelve el diagnóstico de la ME, la notificación a la CNCDO, el mantenimiento del paciente, la comunicación de lo ocurrido a la familia y la solicitud de la donación, así como de las fases para captación y trasplante de órganos, necesitan no sólo del equipo de enfermería, sino principalmente de un equipo multiprofesional que esté involucrado todo el tiempo en el proceso y prestando atención a las necesidades que el paciente y familia requieren habiendo una necesidad de interacción entre los equipos para que el proceso fluya para satisfacer a todas las partes involucradas, pues la asistencia adecuada es indispensable para la efectivación de la donación.

\section{CONCLUSIÓN}

Es evidente en este estudio una brecha entre la afirmación de sentirse preparado para asistir a los pacientes en ME y las respuestas sobre los criterios evaluados en el diagnóstico de ME, principales cuidados generales y específicos prestados y las 
etapas del proceso de donación de órganos y tejidos entre los profesionales de enfermería estudiados.

Pocas etapas del proceso obtuvieron respuestas superiores al $70,0 \%$ y ningún profesional listó todas las etapas fundamentales tanto para el diagnóstico de ME, mantenimiento del PD y las fases que componen el proceso de donación. Evidenciando la falta de conocimiento teórico-práctico del equipo de enfermería estudiado, demostrando la necesidad de invertir en estrategias educativas.

El conocimiento del proceso de donación de órganos y tejidos y de las posibles alteraciones del paciente en ME podrá posibilitar un mejor mantenimiento de los órganos y tejidos para trasplante y la efectivación de las donaciones, ya que el conocimiento es uno de los factores determinantes para el éxito de los programas de trasplantes.

Cabe al enfermero y a su equipo servirse de estrategias de aprendizaje en su proceso de trabajo en asociación con los demás profesionales de salud y con la población para ayudar en el cambio de las actitudes y sensibilización, relacionadas con el proceso de donación de órganos y tejidos, especialmente a través de la formación permanente, con cursos de actualización y campañas de educación en salud a la población enfatizando la importância de la donación.

\section{REFERENCIAS}

1. Lima AAF, Silva MJP, Pereira LL. Sofrimento e contradição: o significado da morte e do morrer para enfermeiros que trabalham no processo de doação de órgãos para transplante. Enfermería Global [Internet]. 2009 [cited 2012 dez 01]; 15:1-17. Available from: http://scielo.isciii.es/pdf/eg/n15/pt clinica1.pdf

2. Lei N. 9.434, de 04 de fevereiro de 1997. Dispõe sobre a remoção de órgãos, tecidos e partes do corpo humano para fins de transplante e tratamento e dá outras providências. Diário Oficial da União (Brasília). 1997 Jul 01. Available from: http://www.planalto.gov.br/ccivil 03/leis/19434.htm

3. Lei N. 10.211, de 23 de março de 2001. Altera dispositivos da Lei n. 9.434, de 4 de fevereiro de 1997, que dispõe sobre a remoção de órgãos, tecidos e partes do corpo humano para fins de transplante e tratamento. Diário Oficial da União (Brasília). 2001 Mar 23. [cited 2013 jan 13] Available from: http://www.planalto.gov.br/ccivil 03/leis/LEIS 2001/L10211.htm

4. Conselho Federal de Medicina (CFM). Resolução CFM no 1.480/1997. Critérios para diagnóstico de morte encefálica. Brasília (Brasil): CFM; 1997. [cited 2012 jan 13] Available from: http://www.portalmedico.org.br/resolucoes/cfm/1997/1480 1997.htm

5. Brasil. Ministério da Saúde. Agência Nacional de Vigilância Sanitária. Resolução RDC $n^{\circ}$ 7, de 24 de fevereiro de 2010. Dispõe sobre os requisitos mínimos para funcionamento de Unidades de Terapia Intensiva e dá outras providências. Ministério da Saúde. Brasília; 2010. [cited 2012 jan 04] Available from: http://www.saude.mg.gov.br/atos normativos/legislacao-sanitaria/estabelecimentosde-saude/uti/RDC-7 ANVISA\%20240210.pdf/

6. Guido LA, Bianchi ERF, Linch GFC. Coping among nurses of the operating room and recovery room. Rev Enferm UFPE On Line [Internet]. 2009 [cited 2013 jan 04]; 3(4):823-30.

Available from: http://www.revista.ufpe.br/revistaenfermagem/index.php/revista/article/view/90/pdf 94 $\underline{5}$ 
7. Ribeiro AS, Gabatz RIB, Neves ET, Padoin SMM. Caracterização de acidente com material perfurocortante e a percepção da equipe de enfermagem. Cogitare Enferm [Internet]. 2009 oct/dec [cited 2012 dez 01]; 14(4):660-6. Available from: http://ojs.c3sl.ufpr.br/ojs2/index.php/cogitare/article/view/16379/10860

8. Maia BO, Amorim JS. Morte encefálica: conhecimento de acadêmicos de enfermagem e medicina. JBT J Bras Transpl [Internet]. 2009 [cited 2012 dez 02]; 12(2):1088-91. Available

http://www.abto.org.br/abtov03/Upload/file/JBT/2009/2.pdf

9. Albuquerque FNA, Silva LMS, Borges MCLA, Janebro ASI, Lima LL. Organs and tissues transplantation: analysis of nurses' performance in the process of donation and capture. R. Pesq: Cuid Fundam online [Internet]. 2011 [cited 2012 dez 02]; 3(1):173946. Available from: http://www.seer.unirio.br/index.php/cuidadofundamental/article/view/1278/pdf 372

10. Freire ILS, Mendonça AEO, Pontes VO, Vasconcelos QLDAQ, Torres GV. Morte encefálica e cuidados na manutenção do potencial doador de órgãos e tecidos para transplante.

Rev. Eletr. Enf. [Internet]. 2012 oct/dec [cited 2012 dez 02]; 14(4):903-12. Available from: http://www.fen.ufg.br/revista/v14/n4/v14n4a19.htm

11. Garcia VD. A política de transplantes no Brasil. Revista da AMRIGS [Internet]. 2006 [cited 2012 dez 02]; 50(4):313-20. Available from: http://www.amrigs.org.br/revista/50-04/aesp01.pdf

12. Pereira AW, Fernandes RC, Soler RC. Diretrizes básicas para captação e retirada de múltiplos órgãos e tecidos da associação brasileira de transplante de órgãos. Associação Brasileira de Transplante de Órgãos [Internet]. 2009 [cited 2013 jan 04]. São Paulo: ABTO. Available from: http://www.abto.org.br/abtov03/Upload/pdf/livro.pdf 13. Amorim VCD, Avelar TABA, Brandão GMON. A otimização da assistência de enfermagem ao paciente em morte encefálica: potencial doador de múltiplos órgãos. Rev enferm UFPE on line [Internet]. 2010 [cited 2012 dez 02]; 4(1):221-29. Available from: http://www.revista.ufpe.br/revistaenfermagem/index.php/revista

14. Guetti NR, Marques IR. Assistência de enfermagem ao potencial doador de órgãos em morte encefálica. Rev Bras Enferm [Internet]. 2008 jan/fev [cited 2013 jan 04]; 61 (1):91-7. Available from: http://www.scielo.br/pdf/reben/v61n1/14.pdf

15. Mendonça AS, Castro DC, Brasileiro ME. Assistência de enfermagem na manutenção do potencial doador de órgãos. Revista Eletrônica de Enfermagem do Centro de Estudos de Enfermagem e Nutrição [Internet]. 2010 jan/jul [cited 2013 jan 04]; 1(1):1-15. http://www.ceen.com.br/conteudo/downloads/4552 52.pdf

16. D'Império F. Morte encefálica, cuidados ao doador de órgãos e transplante de pulmão. Rev bras ter intensiva [Internet]. 2007 jan/ mar [cited 2013 jan 04]; 19(1):7484. Available from: http://www.rbti.org.br/rbti/download/artigo 201061416549.pdf

17. Brasil. Ministério da Saúde. Sistema Nacional de Transplantes - SNT, 2010.

18. Brasil. Ministério da Saúde. Secretaria de atenção à Saúde. Nota Informativa № 03/2011, 04 de maio de 2011.

19. Cinque VM, Bianchi, ERF. A tomada de decisão das famílias para a doação de órgãos. Cogitare Enferm [Internet]. 2010 jan/mar [cited 2013 mar 04]; 15(1):69-73. Available from: http://ojs.c3sl.ufpr.br/ojs2/index.php/cogitare/article/view/17174/11309 20. Domingos GR, Boer LA, Possamai FP. Doação e captação de órgãos de pacientes com morte encefálica. Enfermagem Brasil [Internet]. 2010 jul/ago [cited 2013 mar 04]; 9(4):206-12 Available from: http://www.atlanticaeditora.com.br/index.php?option=com content\&view=article\&id=10 92:eb-v9n4-artigo-2\&catid=139\&ltemid=68 
(c) COPYRIGHT Servicio de Publicaciones - Universidad de Murcia 